${ }^{1}$ Interdepartmental Division of Critical Care Medicine, University of Toronto, Toronto, Canada

${ }^{2}$ Departments of Medicine and Clinical Epidemiology and Biostatistics, McMaster University, Hamilton, Canada

Correspondence to: N KJ Adhikari neill.adhikari@sunnybrook.ca

doi: 10.1136/bmi.39139.716794.55

\title{
Effect of nitric oxide on oxygenation and mortality in acute lung injury: systematic review and meta-analysis
}

Neill KJ Adhikari, lecturer, ${ }^{1}$ Karen E A Burns, assistant professor, ${ }^{1}$ Jan O Friedrich, assistant professor, ${ }^{1}$ John T Granton, associate professor, ${ }^{1}$ Deborah J Cook, professor, ${ }^{2}$ Maureen 0 Meade, associate professor ${ }^{2}$

\section{ABSTRACT}

Objective To review the literature on the use of inhaled nitric oxide to treat acute lung injury/acute respiratory distress syndrome (ALI/ARDS) and to summarise the effects of nitric oxide, compared with placebo or usual care without nitric oxide, in adults and children with ALI or ARDS.

Design Systematic review and meta-analysis.

Data sources Medline, CINAHL, Embase, and CENTRAL (to October 2006), proceedings from four conferences, and additional information from authors of 10 trials.

Review methods Two reviewers independently selected parallel group randomised controlled trials comparing nitric oxide with control and extracted data related to study methods, clinical and physiological outcomes, and adverse events.

Main outcome measures Mortality, duration of ventilation, oxygenation, pulmonary arterial pressure, adverse events.

Results 12 trials randomly assigning 1237 patients met inclusion criteria. Overall methodological quality was good. Using random effects models, we found no significant effect of nitric oxide on hospital mortality (risk ratio $1.10,95 \%$ confidence interval 0.94 to 1.30 ), duration of ventilation, or ventilator-free days. On day one of treatment, nitric oxide increased the ratio of partial pressure of oxygen to fraction of inspired oxygen $\left(\mathrm{PaO}_{2} /\right.$ $\mathrm{FiO}_{2}$ ratio) (13\%, 4\% to $23 \%$ ) and decreased the oxygenation index (14\%, $2 \%$ to $25 \%$ ). Some evidence suggested that improvements in oxygenation persisted until day four. There was no effect on mean pulmonary arterial pressure. Patients receiving nitric oxide had an increased risk of developing renal dysfunction (1.50, 1.11 to 2.02).

Conclusions Nitric oxide is associated with limited improvement in oxygenation in patients with ALI or ARDS but confers no mortality benefit and may cause harm. We do not recommend its routine use in these severely ill patients.

\section{INTRODUCTION}

Acute lung injury (ALI) and acute respiratory distress syndrome (ARDS), defined by acute hypoxaemia and bilateral lung infiltrates on radiography without left atrial hypertension, ${ }^{1}$ are characterised by inflammation of the alveolar-capillary membrane triggered by various insults. ${ }^{2}$ Because the pathophysiology involves mismatching of ventilation and perfusion and pulmonary hypertension, the possibility of using inhaled nitric oxide (NO) generated considerable interest. ${ }^{3}$ Nitric oxide is a selective pulmonary vasodilator and has anti-inflammatory properties. ${ }^{45}$ Based on limited data on efficacy, clinicians rapidly adopted this therapy; 63\% of European intensive care specialists surveyed in 1997 reported using it, primarily for ALI or ARDS. ${ }^{6}$ A more recent survey of specialists in Ontario, Canada, found that a substantial proportion (39\%) reported using nitric oxide at least sometimes in selected patients with ARDS. ${ }^{7}$

A systematic review and meta-analysis of nitric oxide published in $2003^{89}$ that included five randomised controlled trials $\mathrm{s}^{\mathrm{w} 3-\mathrm{w} 7}$ found no effect on mortality or ventilator-free days; one trial showed improved oxygenation. $^{\text {w3 }}$ Because confidence intervals were wide, the authors concluded that the effects of nitric oxide on morbidity and mortality were uncertain. We have incorporated data from new randomised controlled trials to evaluate the effects of nitric oxide on pulmonary physiology (oxygenation and pulmonary arterial pressure) and important clinical outcomes

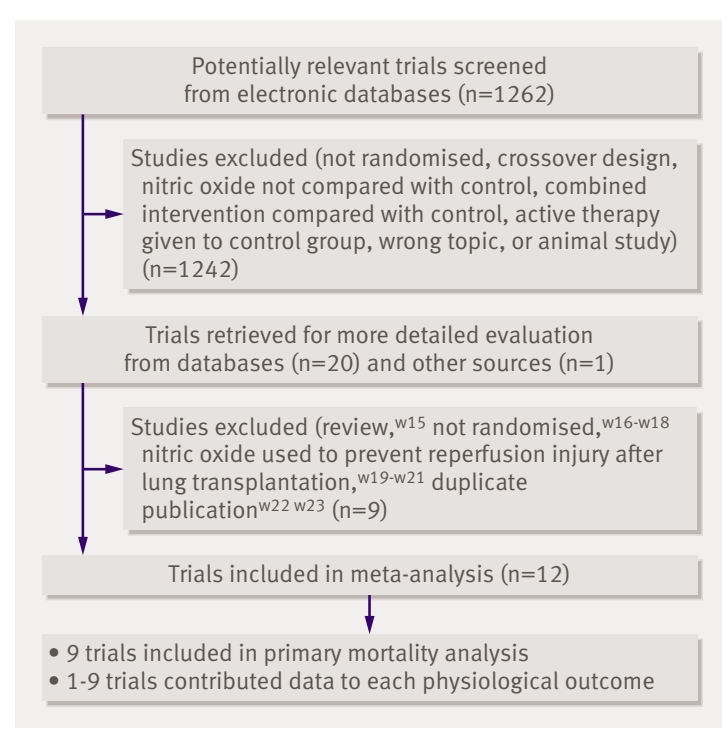

Fig 1 Number of trials evaluated at each stage of the systematic review 
(mortality, duration of ventilation, and adverse effects) in patients with established ALI or ARDS.

\section{METHODS}

\section{Search strategy}

We electronically searched Medline, CINAHL, Embase, and CENTRAL (to October 2006), limiting citations to randomised controlled trials. We also searched proceedings of four conferences (19942006), screened bibliographies of retrieved studies and recent review articles, ${ }^{10-18}$ and contacted content experts to identify additional trials. There were no language restrictions. Further details of the search strategy and other aspects of study methods are on bmj.com.

\section{Study selection}

Two reviewers independently screened studies for inclusion, retrieved potentially relevant studies, and decided on study eligibility. We selected parallel group trials that enrolled adults or children (excluding neonates), with $\geq 80 \%$ of patients or a separately reported subgroup having ALI or ARDS (using

\section{Table 1 | Details of randomised trials of inhaled nitric oxide (NO) in patients with acute lung injury (ALI) and acute respiratory distress syndrome (ARDS)}

Author (funding*)

Day, ${ }^{w 1} 1997$ (not for profit)

Schwebel, ${ }^{\text {w2 }} 1997$ (not for profit; industry supplied gas)

Dellinger, ${ }^{\text {w3 }} 1998$ (industry)

Michael, ${ }^{\text {44 }} 1998$ (not for profit)

Troncy, ${ }^{\text {w5 }} 1998$ (not for profit)

Dobyns, ${ }^{\text {w6 }} 1999$ (not for profit)

supplied gas)

Mehta, ${ }^{\text {w9 }} 2001$ (not for profit and industry)

Gerlach, ${ }^{\text {w10 }} 2003$ (not for profit)

Park, ${ }^{\text {w11 }} 2003$ (not reported)

\section{Population}

24 children, 1 centre. Acute bilateral CXR infiltrates, $\mathrm{PEEP}>6 \mathrm{~cm} \mathrm{H} \mathrm{H}_{2} \mathrm{O}, \mathrm{FiO}_{2}>0.5$ for $>12$

hours. Enrolment $\leq 48 \mathrm{~h}$ after meeting study criteria

19 adults, 17 centres. Any CXR infiltrates, P/F 10 ppm for 17 hours, then at clinician's $<200 \mathrm{~mm} \mathrm{Hg}, 10<\mathrm{PAOP}<18 \mathrm{~mm} \mathrm{Hg}, 6<\mathrm{PEEP}<10$ discretion; mean 4.6 days (range 1.25 to 11 ) $\mathrm{cm} \mathrm{H}_{2} \mathrm{O}$. Duration of ARDS $\leq 24$ hours

177 adults, 30 centres. AECC criteria for ARDS and $\mathrm{FiO}_{2} \geq 0.5$, PEEP $\geq 8 \mathrm{~cm} \mathrm{H}_{2} \mathrm{O}$. Duration of ARDS $\leq 72$ hours

40 patients, 1 centre; $37 / 40 \geq 18$ years. AECC $5,10,15,20$ ppm every 6 hours for 24 hours criteria for ARDS except $P / F \leq 150 \mathrm{~mm} \mathrm{Hg}$ and then clinically adjusted; mean dose $13 \mathrm{ppm}$, $\mathrm{FiO}_{2} \geq 0.8$ for $\geq 12$ hours or $\geq 0.65$ for $\geq 24$ hours tapered if oxygenation not improved by 72 hours

30 adults, 1 centre. Lung injury score ${ }^{30} \geq 2.5$ Initial titration $(2.5,5,10,20,30,40$ ppm every $10 \mathrm{~min}$ ) and daily re-titration; mean dose $5.3 \mathrm{ppm}$. Duration: until oxygenation and PEEP criteria met; mean 8 (SD 5) days $10 \mathrm{ppm}$ for 72 hours, then weaned if failure criteria not met

108 children ( $>1$ month old, median age 2.5 years), 7 centres. Any CXR infiltrates, $\mathrm{OI} \geq 15$ on 2 arterial blood gases within 6 hours (mean duration of ventilation before randomisation 3.5 days in NO group, 3.7 days in control group)

180 adults, 43 centres. Any CXR infiltrates, $\mathrm{P} / \mathrm{F} \leq 165 \mathrm{~mm} \mathrm{Hg}, \mathrm{PEEP} \geq 5 \mathrm{~cm} \mathrm{H}_{2} \mathrm{O}$, mean airway pressure $>10 \mathrm{~cm} \mathrm{H}_{2} \mathrm{O}$. Duration of ventilation $0.75-4$ days. NO respondert

203 adults, 23 centres. AECC criteria for ARDS, lung injury score ${ }^{30} 2-3$ after 24 hours of "therapeutic optimisation" (mean duration of ventilation before randomisation: 5.3 days in NO group, 5.9 days in control group)

14 adults, 1 centre. Bilateral CXR infiltrates, $\mathrm{P} / \mathrm{F}<200 \mathrm{~mm} \mathrm{Hg}, \mathrm{PEEP} \geq 8 \mathrm{~cm} \mathrm{H} \mathrm{H}_{2} \mathrm{O}$, PAOP $<18 \mathrm{~mm} \mathrm{Hg}$. Duration of ARDS $\leq 5$ days

40 adults, 1 centre. Bilateral CXR infiltrates, $\mathrm{P} / \mathrm{F} \leq 150 \mathrm{~mm} \mathrm{Hg}, \mathrm{PEEP} \geq 10 \mathrm{~cm} \mathrm{H}_{2} \mathrm{O}$, PAOP $\leq 18 \mathrm{~mm} \mathrm{Hg}$. Duration of ventilation $\geq 48$ hours with $\mathrm{FiO}_{2} \geq 0.6$ (median duration of ventilation before randomisation: 14 days in NO group, 11.5 days in control group)

17 adults, 1 centre. AECC criteria for ARDS Duration of ARDS $\leq 2$ days
1-40 ppm ("lowest effective dose"); mean dose 9 (SD 8) ppm, until end point met (reversal of ALI or severe respiratory failure), up to 30 days; mean 9 (SD 6) days

10 ppm, until oxygenation and PEEP criteria

met; median 5 days

Daily titration $(5,10,20 \mathrm{ppm}$ every $30 \mathrm{~min})$ for Usual care. No crossovers

4 days. Most received 5-10 ppm on day 2-4;

continued until oxygenation criteria met;

mean 8 (SD 9) days

10 ppm (with daily dose response analysis) Usual care. No crossovers until weaning initiated NO)

Control group and crossovers

Usual care. All patients randomised to control received NO 10 ppm after 24 hours; no crossovers before 24 hours

Placebo gas (nitrogen). Crossovers mandated before 17 hours if $P / F \leq 100 \mathrm{~mm} \mathrm{Hg}$ and permitted thereafter (at least 5/10 patients randomised to control received $\mathrm{NO}$ )

Placebo gas (nitrogen). No crossovers

Usual care. Patients with oxygenation failure received NO (2 patients before 72 hours and 7 patients after 72 hours, of 20 randomised to control)

Usual care. No crossovers

Usual care. Patients meeting failure criteria could receive NO (27/55 patients randomised to control met failure criteria and 2 other patients withdrawn from control group; 29 patients likely received NO)

Usual care. Patients meeting severe respiratory failure criteria could receive NO (6/ 87 patients randomised to control received

Placebo gas (nitrogen). Patients meeting failure criteria crossed to other group (19/105 patients randomised to control and $12 / 98$ patients randomised to $\mathrm{NO}$ crossed over) 
authors' definitions). Included trials compared nitric oxide with placebo or usual treatment (not prevention) for ALI or ARDS and reported mortality (at any time), duration of ventilation, ventilator-free days, or pulmonary physiological parameters on days one to four of treatment $\left(\mathrm{PaO}_{2}\right.$ (partial pressure of oxygen) $/ \mathrm{FiO}_{2}$ (fraction of inspired oxygen); oxygenation index, defined as $100 \times$ mean airway pressure/ $\left(\mathrm{PaO}_{2} / \mathrm{FiO}_{2}\right)$; mean pulmonary arterial pressure). We included trials with cointerventions applied equally in both groups. We assessed agreement between reviewers for trial eligibility using Cohen's $\kappa .{ }^{19}$

Data abstraction and validity assessment

Two reviewers independently abstracted data and methods from included trials. We resolved by consensus any disagreements that remained after contacting trial authors. From included studies we abstracted method of randomisation and allocation concealment, blinding of caregivers and outcomes assessors, and number of withdrawals after randomisation and determined whether mechanical ventilation, weaning, and sedation were standardised or applied equally in treatment groups.

We attempted to contact authors of all included trials to request additional data and clarify data and methods if necessary.

\section{Quantitative data synthesis}

Our primary outcome was mortality in hospital (or, if not available, mortality in the intensive care unit or at 28 or 30 days). We decided a priori to combine trials with less than half of patients crossing over from control to nitric oxide arms in analyses of clinical outcomes. Our analyses adhered to the intention to treat principle. In studies with two or more nitric oxide groups receiving different doses, we combined data to determine an overall effect for the nitric oxide group.

Secondary outcomes included duration of ventilation, ventilator-free days to 28 or 30 days, and pulmonary physiology. We decided post hoc to combine data on renal dysfunction after obtaining outcomes for most randomised patients, but we describe other adverse events qualitatively.

Table 2 | Scientific quality of trials of inhaled nitric oxide (NO) in patients with acute lung injury (ALI) and acute respiratory distress syndrome (ARDS)*

\begin{tabular}{|c|c|c|c|c|}
\hline Author & $\begin{array}{l}\text { Allocation } \\
\text { concealment }\end{array}$ & Blinding & Ventilation & Other cointerventions \\
\hline Day, w1 1997 & $\begin{array}{l}\text { Blinded draw of } 1 \text { lot per } \\
\text { eligible patient }\end{array}$ & None & Clinician discretion & Not described \\
\hline Schwebel,w2 1997 & $\begin{array}{l}\text { Table of gas cylinder } \\
\text { codes (revealed in } \\
\text { sequence) }\end{array}$ & $\begin{array}{l}\text { Clinicians, outcomes } \\
\text { assessors }\end{array}$ & $\begin{array}{l}\text { Protocol (no details) for } 17 \text { hours; } \\
\text { clinician's discretion thereafter }\end{array}$ & Not described \\
\hline Dellinger, w3 1998 & $\begin{array}{l}\text { Sealed, opaque } \\
\text { envelopes }\end{array}$ & $\begin{array}{l}\text { Clinicianst, } \\
\text { outcomes assessors }\end{array}$ & $\begin{array}{l}\text { Guideline (Pplat } \leq 35 \mathrm{~cm} \mathrm{H}_{2} \mathrm{O} \text {; PEEP to } \\
\text { optimise compliance; } \mathrm{FiO}_{2} \text { minimised) }\end{array}$ & $\begin{array}{l}\text { More patients in NO group received } \\
\text { corticosteroids after day } 6(20 / 112 v \\
6 / 57)\end{array}$ \\
\hline Michael, ${ }^{\text {w4 }} 1998$ & Not reported & None & $\begin{array}{l}\text { Clinician discretion; mode unchanged } \\
\text { for } 72 \text { hours; mean PEEP similar } \\
\text { between groups for } 72 \text { hours }\end{array}$ & Not described \\
\hline Troncy, w5 1998 & Envelopesł & None & $\begin{array}{l}\text { Protocol }\left(\mathrm{V}_{\mathrm{T}} 10 \mathrm{ml} / \mathrm{kg} \text { and goal } \mathrm{PaCO}_{2}\right. \\
35-45 \mathrm{~mm} \mathrm{Hg} \text {; maximum PEEP } 15 \mathrm{~cm} \\
\left.\mathrm{H}_{2} \mathrm{O} \text { and goal } \mathrm{PaO}_{2}>85 \mathrm{~mm} \mathrm{Hg}\right)\end{array}$ & $\begin{array}{l}\text { Sedation, blood transfusion, and } \\
\text { nutrition protocols. No prone } \\
\text { ventilation in any patient }\end{array}$ \\
\hline Dobyns, w6 1999 & Envelopesł & $\begin{array}{l}\text { Clinicianst, } \\
\text { outcomes assessors }\end{array}$ & $\begin{array}{l}\text { Guideline ("open lung approach" with } \\
\text { Ppk } \leq 35-40 \mathrm{~cm} \mathrm{H}_{2} \mathrm{O}, V_{\mathrm{T}} \text { limitation, } \\
\text { titrated PEEP; HFOV by clinician } \\
\text { discretion) }\end{array}$ & Not described \\
\hline Lundin, $^{\text {w7 }} 1999$ & Central & None & Clinician discretion & Not described \\
\hline Payen, ${ }^{\text {w8 }} 1999$ & Central & $\begin{array}{l}\text { Clinicians, outcomes } \\
\text { assessors }\end{array}$ & $\begin{array}{l}\text { Guideline before randomisation; } \\
\text { unclear if applied afterwards }\left(\mathrm{V}_{\mathrm{T}} \text {, Pplat, }\right. \\
\text { Ppk limitation; various recruitment } \\
\text { strategies) }\end{array}$ & Not described \\
\hline Mehta, ${ }^{\text {w9 }} 2001$ & No§ & None & Clinician discretion & No prone ventilation in any patient \\
\hline Gerlach, ${ }^{\text {w10 }} 2003$ & Envelopesł & None & Protocol (no details) & $\begin{array}{l}\text { Protocol for prone ventilation and } \\
\text { extracorporeal membrane } \\
\text { oxygenation }\end{array}$ \\
\hline Park, ${ }^{\text {w11 }} 2003$ & $\begin{array}{l}\text { One random number } \\
\text { generated when patient } \\
\text { eligible }\end{array}$ & None & $\begin{array}{l}\text { Protocol }\left(\mathrm{V}_{\mathrm{T}} 6 \mathrm{ml} / \mathrm{kg} ; \text { Pplat } \leq 30 \mathrm{~cm} \mathrm{H}_{2} \mathrm{O} \text {; }\right. \\
\left.\text { PEEP to optimise } \mathrm{PaO}_{2} ; \mathrm{FiO}_{2} \text { minimised }\right)\end{array}$ & $\begin{array}{l}\text { Weaning protocol. No prone } \\
\text { ventilation in any patient }\end{array}$ \\
\hline Taylor, ${ }^{w 12} 2004$ & Central & $\begin{array}{l}\text { Clinicianst, } \\
\text { outcomes assessors }\end{array}$ & $\begin{array}{l}\text { Guideline (Pplat } \leq 35 \mathrm{~cm} \mathrm{H}_{2} \mathrm{O} \text {; PEEP to } \\
\text { optimise compliance; } \mathrm{FiO}_{2} \text { minimised) }\end{array}$ & $\begin{array}{l}\text { Prone ventilation similar (NO: } 10 / \\
192 \text { and control: } 14 / 193), \text { weaning } \\
\text { protocol }\end{array}$ \\
\hline
\end{tabular}

$\mathrm{FiO}_{2}=$ fraction of inspired oxygen; $\mathrm{HFOV}=$ high frequency oscillatory ventilation; $\mathrm{PaO}_{2}=$ partial pressure of arterial oxygen; $\mathrm{PaCO} \mathrm{C}_{2}=$ partial pressure of arterial carbon dioxide; Pplat=plateau airway pressure; $P$ pk=peak airway pressure; $P E E P=$ positive end expiratory pressure; $V_{T}=t i d a l$ volume. *No study reported withdrawals of patients or loss to follow-up for mortality; all patients analysed according to assigned group.

tUnblinded investigator at each site.

‡Envelopes sealed, sequentially numbered, and opaque.

$\S$ Computer generated random numbers. Investigator had access to entire randomisation list at time of randomisation. 


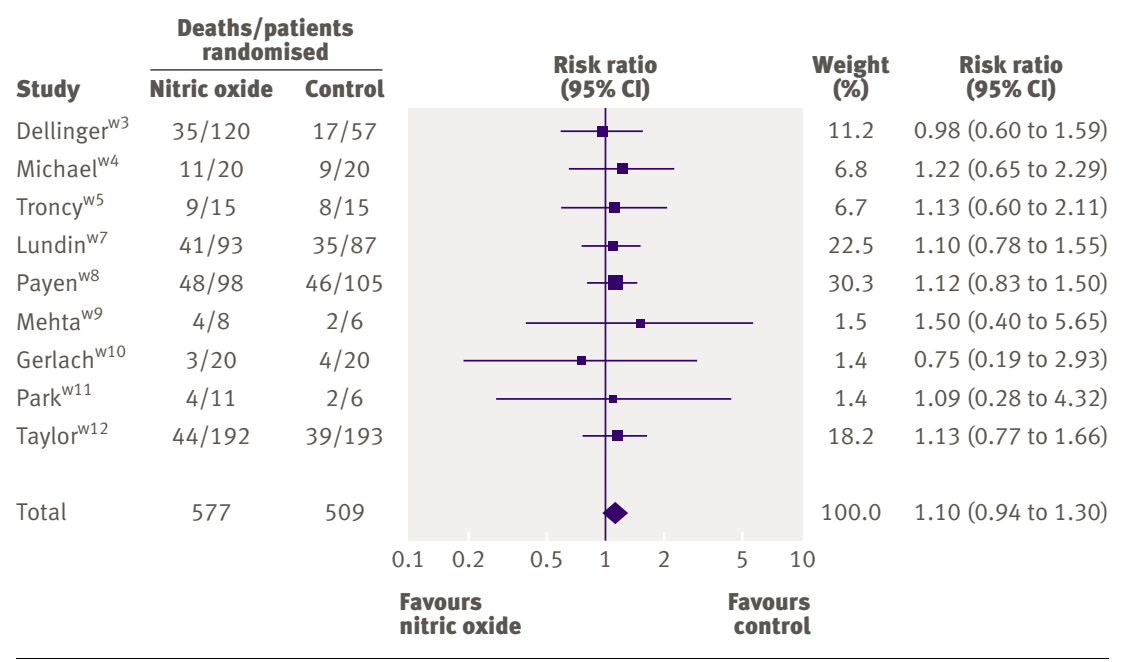

Fig 2 | Effect of nitric oxide on mortality. Weight is the relative contribution of each study to the overall estimate of treatment effect on a log scale assuming a random effects model. Two trials with $\geq 50 \%$ of control patients crossing over to nitric oxide also reported mortality data. ${ }^{\text {w2 }}{ }^{\text {w6 }}$

Inclusion of these trials did not alter summary mortality estimate (risk ratio $1.09,0.94$ to 1.27 )

We used random effects models ${ }^{20}$ implemented in Review Manager 4.2.7 (Cochrane Collaboration, Oxford) for all analyses and considered $\mathrm{P} \leq 0.05$ (two sided) as significant. We report binary outcomes as risk ratios and continuous outcomes as weighted mean differences (measure of absolute change) and ratios of means (measure of relative change). ${ }^{21}$ Summary effect estimates are presented with $95 \%$ confidence intervals.

We assessed homogeneity between studies for each outcome using the Cochran Q statistic, ${ }^{22}$ with $\mathrm{P} \leq 0.10$ indicating significant heterogeneity, ${ }^{23}$ and $I^{2425}$ with suggested thresholds for low $(25 \%-49 \%)$, moderate $(50 \%-74 \%)$, and high $(\geq 75 \%)$ values. We developed several a priori hypotheses to explain significant heterogeneity (excluding duration of ventilation and ventilator-free days), including dose and duration of nitric oxide therapy and whether therapy was restricted to patients whose oxygenation improved acutely ("nitric oxide responders") or to those with ARDS (the more hypoxaemic subset of ALI).

\section{RESULTS}

\section{Trial flow}

Electronic database searches yielded 1262 citations. After evaluating these citations, conference abstracts, review articles, and bibliographies of included trials, we included 12 parallel group randomised controlled trials ${ }^{\mathrm{wl}-\mathrm{wl} 12}$ (fig 1). The two reviewers completely agreed $(\kappa=1)$ on the selection of included studies. We obtained additional information from 10 authors (new clinical $^{\text {w1 w2 w5 w7 w8 w11 }}$ or physiological data ${ }^{\text {w1 } 1 \text { w2 w7 w11 }}$; clarifications of data ${ }^{\mathrm{w} 6 \mathrm{w} 9}$ or methods $\left.^{\mathrm{w1-w3} \text { w5-w11 }}\right)$.

Study characteristics and methodological quality

Table 1 describes the included studies, two of which were published as abstracts only. ${ }^{\mathrm{w} 2 \mathrm{w} 7}$ Data from one trial were distributed in two abstracts, ${ }^{\mathrm{w} 8 \mathrm{w} 13}$ and data from another trial were distributed in two articles. ${ }^{\mathrm{w} 6 \mathrm{w} 14}$ Trials randomised 1237 patients (median 40; range 14-385) with ALI or ARDS. Two trials enrolled only children, ${ }^{\mathrm{w} 1 \mathrm{w} 6}$ one trial included a few children, ${ }^{\mathrm{w} 4}$ and the remaining trials enrolled only adults. All patients met American-European Consensus Conference ${ }^{1}$ oxygenation criteria for ARDS except for one trial that included some patients with ALI. ${ }^{\text {w12 }}$ Seven trials used a fixed dose of nitric oxide (median 10 ppm; range 5-10 ppm), ${ }^{\text {w1 } 22 \text { w6 w8 w10-w12 }}$ and five used the lowest dose to achieve an oxygenation response $^{\mathrm{w} 4 \mathrm{w5} \mathrm{w}^{7} \mathrm{w} 9}$ or randomised patients to different doses. ${ }^{\text {w3 }}$ One trial enrolled only patients whose oxygenation improved after a nitric oxide challenge ("nitric oxide responders"), ${ }^{\text {,7 }}$ and one used a cointervention (a recruitment manoeuvre) in both groups. ${ }^{\text {w11 }}$ Trials continued nitric oxide until prespecified gas exchange end points $^{\mathrm{w1} \text { w3 }} \mathrm{w} 5 \mathrm{w}$ 7-w10 $\mathrm{w} 12$ or for a fixed period of time after which nitric oxide was tapered by using gas exchange criteria ${ }^{\mathrm{w} 4 \mathrm{w} 6}$ or managed at clinicians' discretion. ${ }^{\mathrm{w} 2}$ One trial did not report on criteria for stopping nitric oxide. ${ }^{\text {w11 }}$ The median duration of administration was 6.5 days (range 3.5-9.0 days; data available from five trials $^{\mathrm{w} 5 \mathrm{w} 7-\mathrm{w} 9 \mathrm{w} 11}$ ). One trial randomised patients to nitric oxide or control for 24 hours, after which all patients received nitric oxide. ${ }^{\mathrm{w} 1}$ In five other trials, control patients received nitric oxide as rescue therapy after randomisation if they met prespecified criteria $(<50 \%$ of controls in three trials ${ }^{\mathrm{w} 4 \mathrm{w}^{7} \mathrm{w} 8}$ and $\geq 50 \%$ in two trials $\left.^{\mathrm{w} 2 \mathrm{w} 6}\right)$. Not for profit agencies funded five trials, ${ }^{\text {w1 w4-w6 w10 }}$ industry funded two trials, ${ }^{\text {w3 w12 }}$ both sources funded or supported four trials, ${ }^{\mathrm{w} 2 \mathrm{w} 7 \mathrm{w} 9}$ and one trial did not report this information. ${ }^{\mathrm{w} 11}$

The 12 trials had good scientific quality (table 2). Ten concealed randomisation, ${ }^{\text {w1-w3 }}$ w5-w8 w10-w12 and five

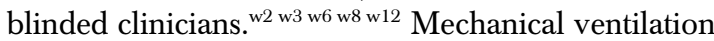
was delivered according to protocol in three unblinded trials ${ }^{\mathrm{w} 5 \mathrm{w} 10 \mathrm{w} 11}$ and one blinded trial ${ }^{\mathrm{w} 2}$ and according to guidelines in three blinded trials. ${ }^{\text {w3 } 6 \text { w12 }}$ Six trials described or standardised at least one other cointervention, such as corticosteroids, ${ }^{\mathrm{w} 3}$ sedation, ${ }^{\mathrm{w} 5}$ prone ventilation, ${ }^{\text {w5 }}$ w9-w12 and ventilator weaning. ${ }^{\mathrm{w} 11 \text { w12 }}$ All trials had complete follow-up, analysed patients by assigned group, and withdrew no one from clinical outcomes analyses. One trial stopped early because of slow enrolment (achieving 45\% of the planned sample $\operatorname{size}^{{ }^{\mathrm{w}}}$ ), and another trial enrolled $75 \%$ of the planned sample, for unclear reasons. ${ }^{\mathrm{w} 12}$

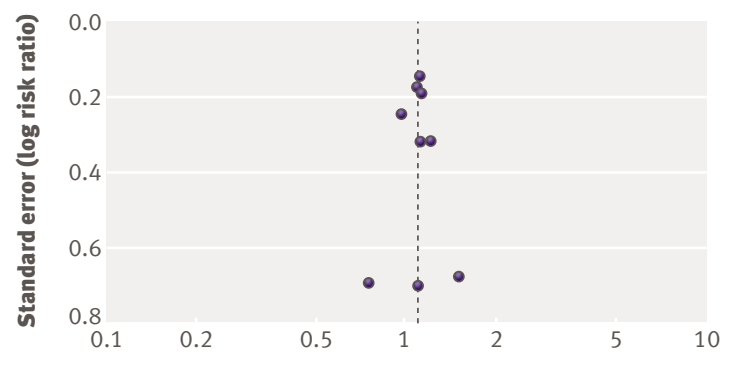

Risk ratio

Fig 3 Funnel plot for outcome of mortality in trials of nitric oxide. Each point represents one trial 
Table 3 | Effects of inhaled nitric oxide (NO) on clinical and physiological outcomes in patients with acute lung injury (ALI) and acute respiratory distress syndrome (ARDS)

\begin{tabular}{|c|c|c|c|c|c|}
\hline \multirow[b]{2}{*}{ Outcome } & \multirow[b]{2}{*}{$\begin{array}{l}\text { No of trials } \\
\text { (patients) }\end{array}$} & \multicolumn{2}{|c|}{ Treatment effect $(95 \% \mathrm{Cl}) ; \mathrm{P}$ value } & \multicolumn{2}{|c|}{$\mathrm{P}$ value for homogeneity; / 2} \\
\hline & & Ratio of means & $\begin{array}{l}\text { Weighted mean } \\
\text { difference }\end{array}$ & $\begin{array}{l}\text { Ratio of } \\
\text { means }\end{array}$ & $\begin{array}{l}\text { Weighted mean } \\
\text { difference }\end{array}$ \\
\hline Mortality* & $9(1086)$ & - & - & - & - \\
\hline Duration of ventilation (days) & $3(237)$ & 1.17 (0.80 to 1.70$) ; 0.41$ & $3.6(-4.0$ to 11.1$) ; 0.36$ & $0.02 ; 76 \%$ & $0.07 ; 63 \%$ \\
\hline Ventilator-free days $\dagger$ & $5(804)$ & 0.94 (0.84 to 1.06$) ; 0.33$ & $-0.6(-1.8$ to 0.7$) ; 0.37$ & $0.71 ; 0 \%$ & $0.66 ; 0 \%$ \\
\hline \multicolumn{6}{|l|}{$\mathrm{PaO}_{2} / \mathrm{FiO}_{2}(\mathrm{~mm} \mathrm{Hg}):$} \\
\hline Day 1 & $9(553)$ & 1.13 (1.04 to 1.23$) ; 0.003$ & 16 (4 to 27$) ; 0.007$ & $0.19 ; 29 \%$ & $0.11 ; 39 \%$ \\
\hline Day 2 & $5(416)$ & 1.07 (1.02 to 1.13$) ; 0.006$ & $9(-3$ to 20$) ; 0.14$ & $0.43 ; 0 \%$ & $0.18 ; 37 \%$ \\
\hline Day 3 & $5(450)$ & 1.05 (0.98 to 1.13$) ; 0.17$ & 7 (-4 to 18$) ; 0.21$ & $0.54 ; 0 \%$ & $0.49 ; 0 \%$ \\
\hline Day 4 & $4(334)$ & 1.07 (1.02 to 1.12$) ; 0.01$ & 15 (4 to 25$) ; 0.009$ & $0.85 ; 0 \%$ & $0.90 ; 0 \%$ \\
\hline \multicolumn{6}{|c|}{ Oxygenation index $(100) \times$ mean airway pressure $/\left(\mathrm{PaO}_{2} / \mathrm{FiO}_{2}\right)\left(\mathrm{cm} \mathrm{H}_{2} \mathrm{O} / \mathrm{mm} \mathrm{Hg}\right)$; } \\
\hline Day 1 & $3(296)$ & $0.86(0.75$ to 0.98$) ; 0.02$ & $-3(-5$ to -0.5$) ; 0.02$ & $0.46 ; 0 \%$ & $0.72 ; 0 \%$ \\
\hline Day 2 & $1(164)$ & 0.81 (0.67 to 0.98$) ; 0.03$ & $-3(-6$ to -0.04$) ; 0.05 \ddagger$ & 一 & 一 \\
\hline Day 3 & $2(245)$ & 0.82 (0.64 to 1.06$) ; 0.13$ & $-3(-7$ to -0.2$) ; 0.04$ & $0.28 ; 16 \%$ & $0.34 ; 0 \%$ \\
\hline Day 4 & $1(134)$ & 0.78 (0.63 to 0.96$) ; 0.02$ & $-4(-8$ to -0.3$) ; 0.03 \ddagger$ & 一 & - \\
\hline \multicolumn{6}{|c|}{ Mean pulmonary arterial pressure $(\mathrm{mm} \mathrm{Hg})$ : } \\
\hline Day 1 & $4(165)$ & 0.95 (0.88 to 1.03$) ; 0.24$ & $-2(-4$ to 1$) ; 0.22$ & $0.27 ; 23 \%$ & $0.27 ; 23 \%$ \\
\hline Day 2 & $3(167)$ & 0.96 (0.89 to 1.02$) ; 0.19$ & $-1(-3$ to 0.6$) ; 0.18$ & $0.64 ; 0 \%$ & $0.68 ; 0 \%$ \\
\hline Day 3 & $2(111)$ & 0.94 (0.87 to 1.02$) ; 0.12$ & $-2(-4$ to 0.5$) ; 0.12$ & $0.95 ; 0 \%$ & $0.97 ; 0 \%$ \\
\hline Day 4 & $3(130)$ & 0.94 (0.88 to 1.01$) ; 0.08$ & $-2(-4$ to 0.3$) ; 0.10$ & $0.81 ; 0 \%$ & $0.72 ; 0 \%$ \\
\hline Renal dysfunction§ & $4(895)$ & - & - & - & - \\
\hline \multicolumn{6}{|c|}{ 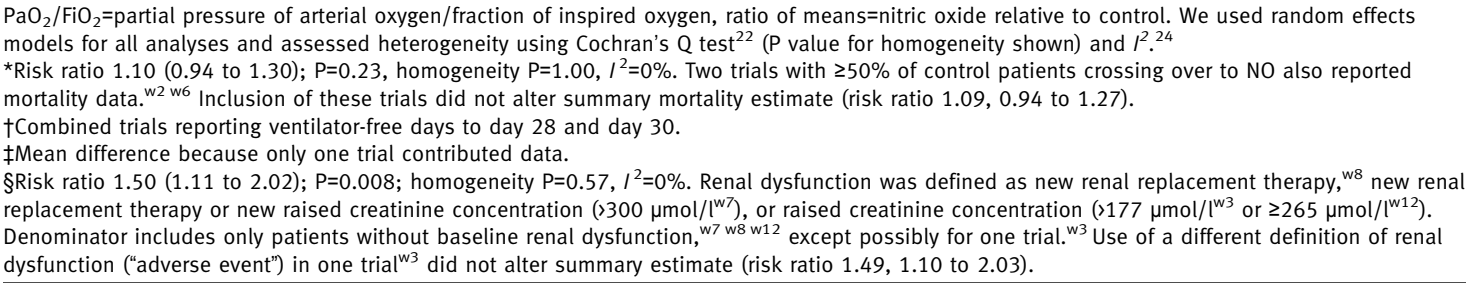 } \\
\hline
\end{tabular}

\section{Data synthesis}

Effect of nitric oxide on clinical outcomes

We combined nine trials ${ }^{\text {w3-w5 }}$ w-w12 in the mortality analysis (three were placebo controlled ${ }^{\mathrm{w} 3} \mathrm{w} 8 \mathrm{w12}$; five used "usual care" controlsw4 w5 w7 w9 w10; one used recruitment manoeuvres in both arms $\left.{ }^{\mathrm{w1} 1}\right)$. We combined three trials that reported duration of ventilation (including all patients ${ }^{\mathrm{w} 10 \mathrm{w} 11}$ or only survivors ${ }^{\mathrm{w} 7}$ ) and five trials reporting ventilator-free days. ${ }^{\text {w3 }} \mathrm{w} 5 \mathrm{w} 8 \mathrm{w11}$ w12

Meta-analyses (table 3) showed that nitric oxide did not affect mortality (risk ratio 1.10; 95\% confidence interval 0.94 to 1.30 ; fig 2 ), duration of ventilation (17\% increase, $-20 \%$ to $70 \% ; 3.6$ additional days, -4.0 to 11.1 days), or ventilator-free days ( $6 \%$ decrease, $-16 \%$ to $6 \%$; 0.6 fewer days, -1.8 to 0.7 days). There was moderate to high heterogeneity between studies for duration of ventilation only.

A funnel plot of standard error versus risk ratio for mortality did not suggest publication bias (fig 3).

\section{Effect of nitric oxide on physiological outcomes}

On the first day of therapy, $\mathrm{NO}$ was associated with small improvements in the $\mathrm{PaO}_{2} / \mathrm{FiO}_{2}$ ratio (nine trials; $13 \%$ higher, $4 \%$ to $23 \% ; 16 \mathrm{~mm} \mathrm{Hg}$ higher, $4 \mathrm{~mm} \mathrm{Hg}$ to $27 \mathrm{~mm} \mathrm{Hg}$; fig 4) and oxygenation index (three trials; $14 \%$ lower, $2 \%$ to $25 \% ; 3 \mathrm{~cm} \mathrm{H}_{2} \mathrm{O} / \mathrm{mm} \mathrm{Hg}$ lower, $0.5 \mathrm{~cm} \mathrm{H}_{2} \mathrm{O} / \mathrm{mm} \mathrm{Hg}$ to $5 \mathrm{~cm} \mathrm{H}_{2} \mathrm{O} / \mathrm{mm} \mathrm{Hg}$; fig 5). Some evidence suggested that improvements in oxygenation in the nitric oxide group persisted beyond day one. The $\mathrm{PaO}_{2} / \mathrm{FiO}_{2}$ ratio was higher on day two and four (but not on day three, and only in the ratio of means analysis on day two). The oxygenation index remained lower on days two, three, and four (only in the weighted mean difference analysis on day three), but only one ${ }^{\mathrm{w} 3}$ (days two and four) or two w3 w6 (day three) trials contributed data. Differences in mean pulmonary arterial pressure were not significant on any day.

There was no evidence of important statistical heterogeneity in the physiological outcomes.

\section{Adverse effects}

Table 4 gives details of adverse effects. All 12 trials gave information about methaemoglobin concentrations. Four nitric oxide patients (of 651 randomised) and three control patients (of 586 randomised) developed $>5 \%$ methaemoglobinaemia. ${ }^{\text {w3 }}{ }^{7}$ w12 One trial reported three patients developing raised nitrogen dioxide concentrations; all had received 80 ppm nitric oxide. ${ }^{\text {w3 }}$ Nitric oxide increased the risk of renal dysfunction in one unblinded ${ }^{\mathrm{w} 7}$ and three blinded ${ }^{\mathrm{w} 3 \mathrm{w} 8 \mathrm{w} 12}$ trials that enrolled $72 \%$ of patients in all included trials (risk ratio $1.50,1.11$ to 2.02 ; fig 6 ). Other adverse events were variably reported, and we did not combine these data. 


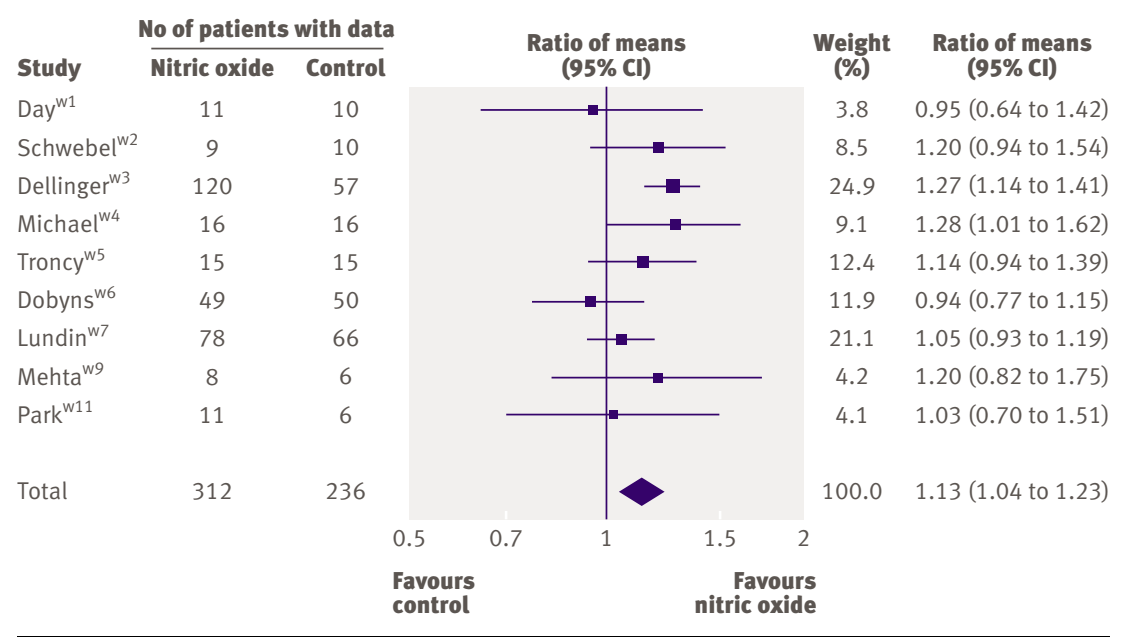

Fig 4 Effect of nitric oxide on $\mathrm{PaO}_{2} / \mathrm{FiO}_{2}$ ratio at 24 hours. Weight is the relative contribution of each study to overall estimate of treatment effect (ratio of means, nitric oxide relative to control) on log scale assuming a random effects model. For some trials, number of patients with data is less than number randomised

\section{DISCUSSION}

The routine use of inhaled nitric oxide is not beneficial for patients with acute lung injury (ALI) and acute respiratory distress syndrome (ARDS). Our meta-analysis included 12 trials that randomly assigned 1237 patients and investigated the effects of inhaled nitric oxide in such patients. We found no benefit of nitric oxide on survival and an increased risk of renal dysfunction. Oxygenation improved over the first 24 hours $\left(13 \%\right.$ relative increase in $\mathrm{PaO}_{2} / \mathrm{FiO}_{2}$ ratio; $14 \%$ decrease in oxygenation index), with some data suggesting improvements to 96 hours. Given the limited physiological improvements and possible harm, we cannot recommend routine use of nitric oxide in these patients.

The trend towards increased mortality in patients receiving nitric oxide was highly consistent across trials, with no trial dominating the meta-analysis. Given the strength and magnitude of this trend, consistency across trials, biological plausibility, ${ }^{18}$ w10 and the finding of other potential adverse effects of nitric oxide (for example, renal failure), our analysis raises concerns about its nitric oxide in this setting.

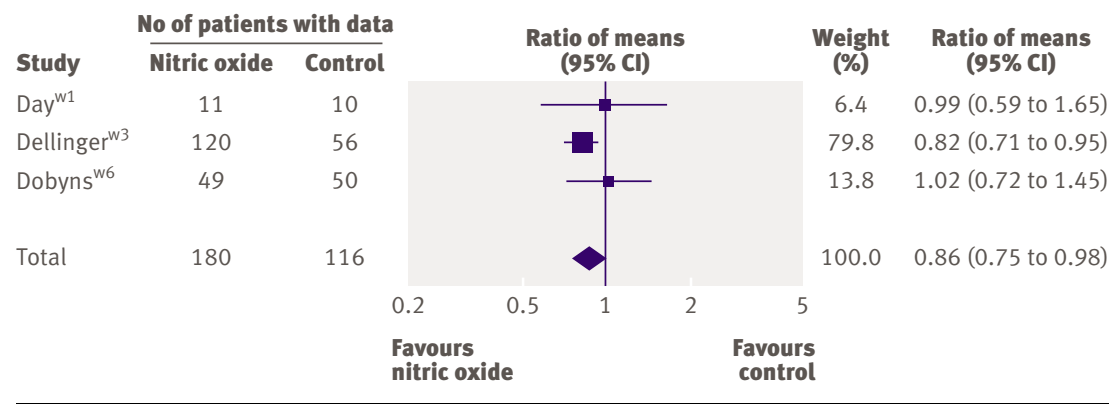

Fig 5 | Effect of nitric oxide on oxygenation index at 24 hours. Weight is the relative contribution of each study to overall estimate of treatment effect (ratio of means, nitric oxide relative to control) on log scale assuming a random effects model. For each trial, number of patients with data is less than number randomised
Adverse events

Descriptive analyses suggest that methemoglobinaemia and raised nitrogen dioxide concentration are not common or clinically important consequences, except possibly in patients receiving high doses (at least $80 \mathrm{ppm}$ ) of nitric oxide for several days. Data from four large trials representing nearly three quarters of all randomised patients showed an increased risk of renal dysfunction in patients receiving nitric oxide. Cautious interpretation is warranted, however, as this result was a post hoc analysis and is potentially subject to publication bias (we were unable to obtain explicit data on renal outcomes in eight of 12 smaller trials, in which this relation may not have been measured or observed). In addition, the potential physiological mechanisms linking administration of inhaled nitric oxide to acute renal dysfunction - inhibition of mitochondrial and enzymatic function and damage to deoxyribonucleic acid and membranes-are controversial because of its simultaneous protective effects on renal blood flow and leukocyte adhesion. ${ }^{26}$

Why nitric oxide may not be beneficial

There are several possible explanations for the lack of benefit of routine administration of nitric oxide in patients with ALI/ARDS. Firstly, short term physiological improvements in oxygenation seem to have no impact on patients' survival, ${ }^{27}$ possibly because oxygenation is not necessarily related to severity of lung injury. Secondly, as most patients with ARDS die of multiple organ failure rather than refractory hypoxaemia, ${ }^{28}$ small changes in oxygenation might not lead to improvements in outcome. Thirdly, the prolonged fixed dosing regimen in most trials may have attenuated benefit over time because of increased sensitisation, dampening the oxygenation benefit while continuing to expose patients to toxic effects such as oxidative damage. ${ }^{18}$ w10 Fourthly, the benefits of nitric oxide may have been overwhelmed by a harmful mechanical ventilation strategy, which perpetuated multiple organ failure. ${ }^{29}$ This, however, would not account for our finding of potential harm. Finally, trials restricting enrolment to patients with an acute oxygenation response to nitric oxide may have found a positive effect on mortality, although this hypothesis was not supported in one trial. ${ }^{\mathrm{w} 7}$

\section{Strengths and limitations}

We used several methods to reduce bias (comprehensive literature search, duplicate data abstraction, prespecified criteria for methodological assessment and analysis) and analysed a comprehensive set of clinical and physiological outcomes. We were unable to obtain any $^{\mathrm{w} 4}$ w12 or complete ${ }^{\mathrm{w} 3}$ additional information from three trials. Considering secondary clinical outcomes, we expected to find variation between trials in duration of ventilation and ventilator-free days related to different populations of patients. We analysed these outcomes, while acknowledging the limited interpretability of this analysis. Finally, given the small number of trials contributing to analyses of 
Author, year

Day, ${ }^{\text {w1 }} 1997$

Methaemoglobin and nitrogen dioxide concentrations No known raised concentrations

Schwebel, ${ }^{\text {w2 }} 1997$

Dellinger,w3 1998

No methaemoglobinaemia

Methaemoglobin concentration $>5 \%$ (none $>7 \%$ ): NO $2.5 \%$ (3/120; 40 ppm, $n=1 ; 80 \mathrm{ppm}, \mathrm{n}=2)$, control $2 \%(1 / 57)$; nitrogen dioxide level $>3$ ppm: NO 2.5\% (3/120; all received 80 ppm), control: none

Michael, ${ }^{\text {w4 }} 1998 \quad$ No methaemoglobinaemia

Troncy, w5 1998

Dobyns, w6 1999

Lundin, ${ }^{\text {w7 }} 1999$

Methaemoglobin concentration $>5 \%$ : none; nitrogen dioxide
No methaemoglobinaemia concentration $>2$ ppm: none

Methaemoglobin concentration $>5 \%$ : NO 1\% (1/93), control 1\% (1/87); median methaemoglobin concentrations over 30 days: NO $0.5 \%-1.2 \%$, control $0.2 \%-1.0 \%$ ("overall lower" than in NO group)
Other adverse effects

None

None

Renal function ("defined by adverse events"): NO 11\% (13/120), control 9\% (5/57); creatinine $>177 \mu \mathrm{mol} / \mathrm{l}$ : NO 17\% (20/120), control 13\% (7/57). Adverse events "possibly" related to study gas: NO 3\% (4/120: myopathy, agitation; abnormal liver enzymes; apnoea, lung haemorrhage, coagulopathy; renal dysfunction), control $2 \%$ (1/57: hypertension). All adverse events: no significant differences

Bleeding. Blood transfusion: NO 5\% (1/20), control 0/20. Intracranial haemorrhage after thrombolytic therapy: NO 5\% (1/20 after thrombolytic therapy) , control 0/20 Not reported

No difference in "intensive care unit-dependent therapies"31

Adverse events related to study gas: NO 1\% (1/93: gastrointestinal bleeding), control 2\% (2/87: coagulopathy, intracranial bleed). Renal function "abnormal": NO $13 \%$ (12/93), control 5\% (4/87). Renal replacement (incident cases): NO 27\% (23/ $84)$, control $13 \%$ (10/79); risk ratio $2.16,1.10$ to 4.25 . Creatinine $>300 \mu \mathrm{mol} / \mathrm{l}$ without renal replacement (incident cases): NO 6\% (5/80), control 3\% (2/74). Other serious adverse events more common in NO group: circulatory failure: NO 31\% (29/ 93), control 20\% (17/87); encephalopathy: NO 3\% (3/93), control none; sepsis: NO $8 \%$ (7/93), control, $3 \%$ (3/87). Other adverse events: no difference in incidence of raised total bilirubin, pneumothorax, or platelet, bleeding or clotting disorders or haemodynamic failure (definitions of haemodynamic $v$ circulatory failure not given)

Payen, ${ }^{\text {w8 }} 1999 \quad$ Methaemoglobin concentrations reported as always acceptable and not
different between groups

Mehta, ${ }^{\text {w9 }} 2001 \quad$ Methaemoglobin concentration $>3 \%$ : none (concentration in 1/8 NO Renal replacement (incident cases): NO 37\% (33/89), control 29\% (26/90); risk ratio $1.28,0.84$ to 1.96 . Bleeding: NO 6\% (6/105), control 3\% (3/98)

patients was $3.8 \%$ before therapy); nitrogen dioxide concentration $>2$ None ppm: none

Gerlach, ${ }^{\text {w10 }} 2003 \quad$ No methaemoglobinaemia; no patients with increased nitrogen dioxide concentrations

No bleeding. No difference between groups in number of additional organ dysfunctions ${ }^{32}$

No methaemoglobinaemia

None

Park, ${ }^{\text {w11 }} 2003$

Methaemoglobin concentration >5\%: NO 0/192, control 0.005\% (1/193); nitrogen dioxide concentration $>2$ ppm: none many physiological outcomes, the tests for heterogeneity were underpowered.

Although our results do not exclude the possibility that some subgroups of patients may benefit from nitric oxide, the consistent lack of a mortality benefit across

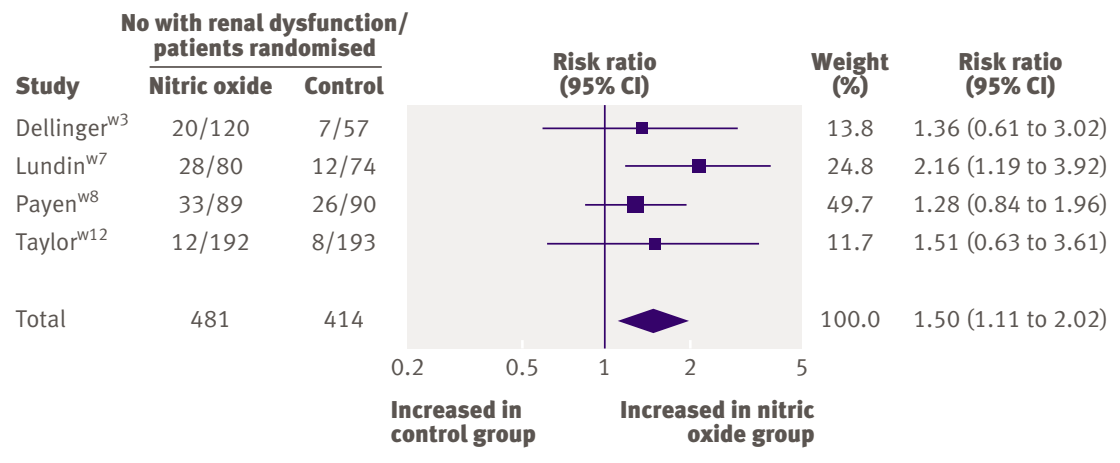

Fig 6 | Effect of nitric oxide on renal dysfunction (defined as new renal replacement therapy, ${ }^{\text {w8 }}$ new renal replacement therapy or new raised creatinine concentration $\left(>300 \mu \mathrm{mol} / \mathrm{l}^{\mathrm{w}} \mathrm{\gamma}\right)$, or raised creatinine concentration $\left(>177 \mu \mathrm{mol} / \mathrm{I}^{\mathrm{w3}}\right.$ or $\left.\left.\geq 265 \mu \mathrm{mol} / \mathrm{I}^{\mathrm{w12}}\right)\right)$. The denominator includes

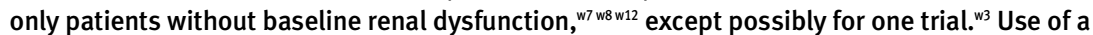
different definition of renal dysfunction ("adverse event") in one trial ${ }^{\text {w3 }}$ did not alter the summary estimate (risk ratio $1.49,1.10$ to 2.03 ). Weight is the relative contribution of each study to overall estimate of treatment effect on log scale assuming a random effects model trials mitigates this possibility. The included trials did not specifically study the issue of nitric oxide as rescue therapy for patients with critically low oxygenation. With nitric oxide, short term improved oxygenation in these patients may create a window for other strategies to improve lung function, such as treatment of the underlying cause of ARDS.

\section{Previous research}

A previous systematic review and meta-analysis of inhaled nitric oxide for acute hypoxaemic respiratory failure $^{89}$ included fewer randomised controlled trials $^{\mathrm{w} 3-\mathrm{w} 7}$ and found no effect on mortality (risk ratio $0.98,95 \%$ confidence interval 0.66 to 1.44 ; two trials, 204 patients). Our report is consistent with this work and extends it by including more trials, thus narrowing the confidence limits around the estimate of mortality. We also provide new estimates of the impact of nitric oxide on other clinical and physiological end points and raise the possibility of harm induced by nitric oxide.

In conclusion, our systematic review and meta-analysis found that inhaled nitric oxide improved oxygenation in patients with ALI and ARDS at 24 hours of 


\section{WHAT IS ALREADY KNOWN ON THIS TOPIC}

Inhaled nitric oxide continues to be used to improve oxygenation in patients with acute lung injury, despite no clear supporting evidence

A previous meta-analysis in 2003 included five randomised trials of nitric oxide; there are now 12 trials

\section{WHAT THIS STUDY ADDS}

Nitric oxide improves oxygenation temporarily but does not improve survival and may cause harm

We do not recommend routine use of nitric oxide in patients with acute lung injury

therapy, with some evidence for a more prolonged effect. Given that the best available evidence suggests no survival advantage and possible increased mortality and renal dysfunction with nitric oxide, we do not recommend its routine use. Despite a lack of evidence for benefit, some clinicians may still consider nitric oxide for life threatening hypoxaemia, in conjunction with other supportive therapies. Given the challenges of enrolling such severely ill patients into large trials, definitive data supporting or refuting a role for nitric oxide in such desperate situations may not be forthcoming, leaving clinicians to rely on their judgment and the current evidence.

We thank Phil Dellinger, Emily Dobyns, Herwig Gerlach, and Sangeeta Mehta for providing additional information about their trials; Pascal Beuret, Gilbert Blaise, Ronald Day, Stefan Lundin, Kwang Joo Park, Didier Payen, and Benoît Vallet for providing additional outcomes data; Natasha Stankovic for assistance in translation; and Jim Julian for constructive comments on an earlier draft of the manuscript.

Contributors: NKJA conceived and designed the study, acquired data, analysed and interpreted data, and drafted the manuscript. KEAB contributed to study design and acquired and interpreted data. JOF acquired and interpreted data. JTG interpreted data. DJC and MOM contributed to study design and interpreted data. All authors revised the manuscript for important intellectual content and approved the final version. NKJA is guarantor.

Funding: None.

Competing interests: None declared.

Ethical approval: Not required.

1 Bernard GR, Artigas A, Brigham KL, Carlet J, Falke K, Hudson L, et al. The American-European Consensus Conference on ARDS. Definitions, mechanisms, relevant outcomes, and clinical trial coordination. Am J Respir Crit Care Med 1994;149:819-24.

2 Ware LB, Matthay MA. The acute respiratory distress syndrome. $N$ Engl J Med 2000;342:1334-49.

3 Furchgott RF. The 1996 Albert Lasker Medical Research Awards. The discovery of endothelium-derived relaxing factor and its importance in the identification of nitric oxide. JAMA 1996;276:1186-8.

4 Gries A, Bode C, Peter K, Herr A, Bohrer H, Motsch J, et al. Inhaled nitric oxide inhibits human platelet aggregation, P-selectin expression, and fibrinogen binding in vitro and in vivo. Circulation 1998;97:1481-7.

5 Kubes P, Suzuki M, Granger DN. Nitric oxide: an endogenous modulator of leukocyte adhesion. Proc Natl Acad Sci U S A 1991;88:4651-5.

6 Beloucif S, Payen D. A European survey of the use of inhaled nitric oxide in the ICU. Working Group on Inhaled NO in the ICU of the European Society of Intensive Care Medicine. Intensive Care Med 1998;24:864-77.
7 Meade MO, Jacka MJ, Cook DJ, Dodek P, Griffith L, Guyatt GH, et al. Survey of interventions for the prevention and treatment of acute respiratory distress syndrome. Crit Care Med 2004:32:946-54.

8 Sokol J, Jacobs SE, Bohn D. Inhaled nitric oxide for acute hypoxic respiratory failure in children and adults: a meta-analysis. Anesth Analg 2003;97:989-98.

9 Sokol J, Jacobs SE, Bohn D. Inhaled nitric oxide for acute hypoxemic respiratory failure in children and adults. Cochrane Database Syst Rev 2003;(1):CD002787.

10 McIntyre RC Jr, Pulido EJ, Bensard DD, Shames BD, Abraham E. Thirty years of clinical trials in acute respiratory distress syndrome. Crit Care Med 2000;28:3314-31.

11 Conner BD, Bernard GR. Acute respiratory distress syndrome. Potential pharmacologic interventions. Clin Chest Med 2000;21:563-87.

12 Brower RG, Ware LB, Berthiaume Y, Matthay MA. Treatment of ARDS Chest 2001;120:1347-67.

13 Dos Santos CC, Chant C, Slutsky AS. Pharmacotherapy of acute respiratory distress syndrome. Expert Opin Pharmacother 2002;3:875-88

14 Cranshaw J, Griffiths MJ, Evans TW. The pulmonary physician in critical care-part 9: non-ventilatory strategies in ARDS. Thorax 2002;57:823-9.

15 Tasaka S, Hasegawa N, Ishizaka A. Pharmacology of acute lung injury. Pulm Pharmacol Ther 2002;15:83-95.

16 Wiedemann HP, Arroliga AC, Komara Jr JJ. Emerging systemic pharmocologic approaches in acute respiratory distress syndrome. Respir Care Clin N Am 2003;9:419-35.

17 Fan E, Mehta S. High-frequency oscillatory ventilation and adjunctive therapies: inhaled nitric oxide and prone positioning. Crit Care Med 2005;33:S182-7.

18 Griffiths MJD, Evans TW. Inhaled nitric oxide therapy in adults. N Eng J Med 2005;353:2683-95.

19 Fleiss JL, Cohen J. The equivalence of weighted kappa and the intraclass correlation coefficient as measures of reliability. Educ Psychol Meas 1973;33:613-9.

20 DerSimonian R, Laird N. Meta-analysis in clinical trials. Control Clin Trials 1986;7:177-88.

21 Friedrich JO, Adhikari N, Herridge MS, Beyene J. Meta-analysis: lowdose dopamine increases urine output but does not prevent renal dysfunction or death. Ann Intern Med 2005;142:510-24.

22 Cochran W. The combination of estimates from different experiments. Biometrics 1954:10:101-29.

23 Berlin JA, Laird NM, Sacks HS, Chalmers TC. A comparison of statistical methods for combining event rates from clinical trials. Stat Med 1989;8:141-51.

24 Higgins JP, Thompson SG. Quantifying heterogeneity in a metaanalysis. Stat Med 2002;21:1539-58.

25 Higgins JP, Thompson SG, Deeks JJ, Altman DG. Measuring inconsistency in meta-analyses. BMJ 2003;327:557-60.

26 Valdivielso JM, Blantz RC. Acute renal failure: is nitric oxide the bad guy? Antioxid Redox Signal 2002;4:925-34.

27 Acute Respiratory Distress Syndrome Network. Ventilation with lowe tidal volumes as compared with traditional tidal volumes for acute lung injury and the acute respiratory distress syndrome. $N$ Engl / Med 2000;342:1301-8.

28 Montgomery AB, Stager MA, Carrico CJ, Hudson LD. Causes of mortality in patients with the adult respiratory distress syndrome. $A m$ Rev Respir Dis 1985;132:485-9.

29 Ranieri VM, Suter PM, Tortorella C, De Tullio R, Dayer JM, Brienza A, et al. Effect of mechanical ventilation on inflammatory mediators in patients with acute respiratory distress syndrome: a randomized controlled trial. JAMA 1999;282:54-61.

30 Murray JF, Matthay MA, Luce JM, Flick MR. An expanded definition of the adult respiratory distress syndrome [Erratum, Am Rev Respir Dis 1989;139:1065]. Am Rev Respir Dis 1988;138:720-3.

31 Pollack MM, Getson PR, Ruttimann UE, Steinhart CM, Kanter RK, Katz RW, et al. Efficiency of intensive care. A comparative analysis of eight pediatric intensive care units. JAMA 1987;258:1481-6.

32 Goris RJ, te Boekhorst TP, Nuytinck JK, Gimbrere JS. Multiple-organ failure. Generalized autodestructive inflammation? Arch Surg 1985;120:1109-15.

Accepted: 23 January 2007 